Tropical Journal of Pharmaceutical Research December 2015; 14 (12): 2239-2246

ISSN: $1596-5996$ (print); 1596-9827 (electronic)

(c) Pharmacotherapy Group, Faculty of Pharmacy, University of Benin, Benin City, 300001 Nigeria.

All rights reserved.

Available online at http://www.tjpr.org

Original Research Article

http://dx.doi.org/10.4314/tjpr.v14i12.13

\title{
Isolation, Identification and Determination of Six Nucleosides and Two Amino Acids from Bamboo Shoots of Gramineae Phyllostachys prominens (W Y Xiong)
}

\author{
Xiao-bo Xu, Yong-de Yue*, Feng Tang, Xue-feng Guo, Jin Wang, Xi Yao, Jia \\ Sun and Hang Xun \\ International Center for Bamboo and Rattan, Beijing 100102, China
}

*For correspondence: Email: yueyd@icbr.ac.cn; Tel: 01084789868

Received: 6 August 2015

Revised accepted: 7 November 2015

\begin{abstract}
Purpose: To develop a method to identify and quantify the compounds in the shoots of four Phyllostachys bamboo species (Gramineae Phyllostachys prominens W. Y. Xiong, Gramineae Phyllostachys iridescins C. Y. Yao Gramineae Phyllostachys pubescens (Carr.) Mitford, Gramineae Phyllostachys praecox C. D. Chu et C. S. Chao. ).

Methods: The compounds in bamboo shoots were isolated and identified by ultraviolet (UV) spectroscopy, mass spectrometry (MS), and nuclear magnetic resonance (NMR). Quantitative analysis was performed by reversed-phase high performance liquid chromatography (RP-HPLC) using a C18 column and a mixture (1:1ratio) of acetonitrile and $15 \mathrm{mM}$ ammonium acetate ( $\mathrm{pH}$ 6.0) as mobile phase. This method was validated for its reproducibility, chemical stability, and recovery.

Results: Six nucleosides and two amino acids were isolated from bamboo shoots, including guanosine, 2'-deoxyguanosine, adenosine, thymidine, uridine, cytidine, tryptophan, and phenylalanine. The HPLC method was rapid and reproducible. The intraday and interday concentrations of the eight identified compounds showed good linearity in the range of $0.22-60.00 \mu \mathrm{g} / \mathrm{mL}$. The relative standard deviation (RSD) for intraday and interday precision for reproducibility and stability was $<3 \%$. The validated method was successfully applied to determine the content of the eight compounds in four different Phyllostachys species.

Conclusion: Adenosine was isolated from bamboo shoots previously, but the isolation of the other seven compounds are reported here for the first time. The method proposed is sensitive and reproducible, and would facilitate studies of nutritional/medicinal compounds in bamboo shoot.
\end{abstract}

Keywords: Bamboo shoots, Phyllostachys prominens, Guanosine, 2'-Deoxyguanosine, Adenosine, Thymidine, Uridine, Cytidine, Tryptophan, Phenylalanine

Tropical Journal of Pharmaceutical Research is indexed by Science Citation Index (SciSearch), Scopus, International Pharmaceutical Abstract, Chemical Abstracts, Embase, Index Copernicus, EBSCO, African Index Medicus, JournalSeek, Journal Citation Reports/Science Edition, Directory of Open Access Journals (DOAJ), African Journal Online, Bioline International, Open-J-Gate and Pharmacy Abstracts

\section{INTRODUCTION}

Bamboo shoot is an important traditional food and medicinal material. The Compendium of Materia Medica in China records many medical uses of bamboo shoot. The chemical composition and active properties of bamboo shoots are attracting the attention of health advocates and scientists [1]. Bamboo shoot has a low fat content and is a rich source of nutrients such as vitamins, amino acids, and antioxidants such as flavones, phenols, and steroids [2]. Bamboo shoot is reported to possess anti-aging, antioxidant, anticancer, antibacterial, and antiviral activities [3]. However, few studies have been performed on bamboo shoots of 
Phyllostachys prominens, which is an important crop species for bamboo shoots [4].

Nucleosides and their bases are involved in the regulation of many physiological processes in the human body and exhibit active functional properties such as antiplatelet aggregation, antiarrhythmic, antioxidant, antiseizure, and antitumor $[5,6]$. Nucleotides and amino acids can be used as indicators to evaluate the quantity of food and medicine. High performance liquid chromatography (HPLC) has been established as a reliable method to identify nucleosides in herbs and food such as Xiaochaihu, edible fungi, Ganoderma, and Ziziphus jujuba [7-10]. A major aim of this study was to extract, isolate, and identify compounds from bamboo shoots of four Phyllostachys species using ultraviolet (UV) spectroscopy, mass spectrometry (MS), nuclear magnetic resonance (NMR), and reversed-phase high performance liquid chromatography (RPHPLC). Another aim was to develop and validate an HPLC-UV method for the identification of the important compounds in bamboo shoot.

\section{EXPERIMENTAL}

\section{Materials and chemicals}

Bamboo shoot samples were collected from Phyllostachys prominens, Phyllostachys iridescens, Phyllostachys pubescens, and Phyllostachys praecox in Hangzhou City (Zhejiang Province, China) in April, 2014. The plants were identified by Professor Chen Shuang-Lin of the Research Institute of Subtropical Forestry (Fuyang, Zhejiang, China).

Bamboo shoots were harvested, shells were removed, and the shoots were washed with distilled water, dried in the shade, and stored in glass bottles at $4{ }^{\circ} \mathrm{C}$ until used. Voucher specimens were deposited in the herbarium of State Forestry Administration Key Open Laboratory, International Center for Bamboo and Rattan (Beijing, China).

\section{Chemical standards}

Guanosine, 2'-deoxyguanosine, adenosine, thymidine, uridine, cytidine, tryptophan, and phenylalanine were obtained from $J$ \& $K$ Scientific Company (Beijing, China). The purities of the standard chemicals were all $>98 \%$.

\section{Equipment}

Preparative HPLC was performed using a Shimadzu LC-6AD instrument with an SPD-20A detector and a YMC-Pack ODS-AQ column (250 $\times 4.6 \mathrm{~mm}, 5 \mu \mathrm{m}$ ). NMR was performed using a Bruker 300 spectrometer. Electrospray ionization (ESI)-MS spectra were obtained using an Agilent 6540 high resolution quadrupole time-of-flight (QTOF) mass spectrometer.

\section{Extraction and isolation of compounds from bamboo shoots}

Dried bamboo shoots $(3.0 \mathrm{~kg})$ were extracted three times with a $10 \mathrm{~L}$ volume of $75 \%$ aqueous ethanol at room temperature. Each extraction was performed for 1 day. The aqueous ethanol extract was evaporated under reduced pressure to yield the residue; the final residue weight was $90 \mathrm{~g}$. The residue components were separated on a macroporous resin column (AB-8, $10 \times 80$ $\mathrm{cm})$ and eluted with an ethanol gradient $(0,15$, 30 and $100 \%$ ) in water. Four fractions (F1 - F4) were collected based on HPLC analysis. Fraction $2(\mathrm{~F} 2,12.0 \mathrm{~g})$ was separated repeatedly on a Sephadex LH-20 column to obtain 25 fractions (E1 $\square$ E25), which were further separated and identified using preparative HPLC analysis. The final analysis identified Compounds 1 - 8. The structures of these compounds were identified using UV spectroscopy, MS, and NMR.

\section{HPLC analysis and determination of compounds 1 - 8}

\section{Preparation of standard marker stock solutions}

Each of the eight standard compounds $(10.0 \mathrm{mg}$ ) was dissolved in $10 \mathrm{ml}$ methanol-water (1:1) in a $10 \mathrm{~mL}$ volumetric flask to make the individual standard stock solutions. The working stock solution (designated as the mixed standard solution) containing the eight identified compounds was formulated by mixing $2.0 \mathrm{~mL}$ of the phenylalanine stock solution and $0.6 \mathrm{~mL}$ of the remaining stock solutions (guanosine, 2'deoxyguanosine, adenosine, thymidine, uridine, cytidine, and tryptophan) in a $10 \mathrm{~mL}$ volumetric flask.

\section{Sample preparation}

Bamboo shoots $(1.0 \mathrm{~g})$ were mixed with $30 \mathrm{~mL}$ of ditilled water, and then ultrasonic extraction was performed at room temperature for $20 \mathrm{~min}$ for three times. The resulting extract was centrifuged at $4,000 \times \mathrm{g}$ for $30 \mathrm{~min}$, and the supernatant was transferred to a new tube. The supernatant was evaporated under reduced pressure and the residue was resuspended in $5 \mathrm{~mL}$ of distilled water, which was transferred to a $10 \mathrm{~mL}$ volumetric flask. This sample was used for HPLC 
analysis; $1 \mathrm{~mL}$ was removed from the flask and filtered through a $0.45 \mu \mathrm{m}$ membrane filter before injection onto the HPLC column.

\section{HPLC analysis}

An XTerra RP C18 column $(5 \mu \mathrm{m}, 250 \times 4.6 \mathrm{~mm})$ and a YMC Hydrosphere C18 column ( $5 \mu \mathrm{m}, 250$ $\times 4.6 \mathrm{~mm}$ ) were used for separation. The mobile phase consisted of Solvent $A$ (acetonitrile) and Solvent B $(15 \mathrm{mM}$ ammonium acetate in water, $\mathrm{pH}$ 6.0). The following gradient was used: $0-11$ min, 5 - $10 \% A ; 11$ - 13 min, $10-15 \% A ; 13-15$ $\min , 15-5 \% A ; 15-18 \mathrm{~min}, 5 \% \mathrm{~A}$. The flow rate was $1.0 \mathrm{~mL} / \mathrm{min}$. The compounds were identified based on their retention times and spectrum against known standards. The external standard method was used for the determinations each compound.

\section{Validation of the method}

A concentration series of the mixed standard solution was prepared to assess the concentrations of the isolated samples. The limit of detection (LOD) and limit of quantitation (LOQ) were measured by duplicate injections of the mixed standard solution based on signal-to-noise ratios $(\mathrm{S} / \mathrm{Ns})$ of 3 and 10 , respectively.

The precision of inter-day and intra-day measurements was determined by repeating the mixed standard solution measurement five times in one day and for five consecutive days. Precision was expressed as relative standard deviation (RSD). To evaluate reproducibility, six independent Phyllostachys prominens samples were analyzed and the results were expressed in terms of RSD.

To confirm the stability, one Phyllostachys prominens sample was analyzed after the sample was left at room temperature for different times $(1,2,3,4,5$, and $6 \mathrm{~d})$, and the results were expressed in terms of RSD. A recovery test was performed by adding three different volumes of the mixed standard solution to three different 1.0 g samples of Phyllostachys prominens. The three replicate samples spiked with different standard contents were extracted and analyzed by HPLC. The recovery rates of the mixed standards were calculated. A control also was analyzed.

\section{Statistical analysis}

All bamboo shoot samples were analyzed in quadruplicate, and experiments were repeated three times. Statistical analysis was conducted using Excel and RSD computed.

\section{RESULTS}

\section{Structures of the identified compounds}

Eight compounds were isolated from bamboo shoot samples and identified as guanosine, 2'deoxyguanosine, adenosine, thymidine, uridine, cytidine, tryptophan, and phenylalanine. Data for structural identifications are presented in the following paragraphs.

\section{Compound 1}

The high resolution electron ionization mass spectrometric (HREIMS) analysis of Compound 1 displayed a molecular ion peak at $\mathrm{m} / \mathrm{z} 282.2407$ $[\mathrm{M}-\mathrm{H}]]^{-}\left(\mathrm{C}_{10} \mathrm{H}_{13} \mathrm{~N}_{5} \mathrm{O}_{5}\right)$. The ${ }^{1} \mathrm{H}$ - and ${ }^{13} \mathrm{C}-\mathrm{NMR}$ spectra were in close agreement with those of a previous report [11]. The ${ }^{1} \mathrm{H}-\mathrm{NMR}\left(\delta, \mathrm{CD}_{3} \mathrm{OD}\right.$, $300 \mathrm{MHz}$ ) spectra revealed the following peaks: $10.60(1 \mathrm{H}$, br. s, NH); $7.94(1 \mathrm{H}, \mathrm{s}, \mathrm{H}-8) ; 6.48(2 \mathrm{H}$, br. s, $\left.-\mathrm{NH}_{2}\right) ; 5.71\left(1 \mathrm{H}, \mathrm{t}, J=8.0 \mathrm{~Hz}, \mathrm{H}-1^{\prime}\right) ; 5.45$ $\left(1 \mathrm{H}, \mathrm{d}, J=6.0 \mathrm{~Hz}, 2^{\prime}-\mathrm{OH}\right) ; 5.26(1 \mathrm{H}, \mathrm{d}, J=4.6$ $\left.\mathrm{Hz}, 3^{\prime}-\mathrm{OH}\right) ; 4.95\left(1 \mathrm{H}, \mathrm{m}, 5^{\prime}-\mathrm{OH}\right) ; 4.41(1 \mathrm{H}, \mathrm{d}, J=$ $\left.5.2 \mathrm{~Hz}, \mathrm{H}-2^{\prime}\right) ; 4.06\left(1 \mathrm{H}, \mathrm{m}, \mathrm{H}-3^{\prime}\right)$; $3.78(1 \mathrm{H}, \mathrm{m}, \mathrm{H}-$ 4'); $3.59\left(1 \mathrm{H}, \mathrm{m}, \mathrm{H}-5^{\prime} \mathrm{a}\right)$; and $3.51\left(1 \mathrm{H}, \mathrm{m}, \mathrm{H}-5^{\prime} \mathrm{b}\right)$. The ${ }^{13} \mathrm{C}$-NMR $\left(\delta, \mathrm{CD}_{3} \mathrm{OD}, 300 \mathrm{MHz}\right)$ spectra revealed the following peaks: $157.9(\mathrm{C}-6) ; 154.1$ (C-2); 151.7 (C-4); 136.0 (C-8); 117.2 (C-5); 86.8 (C-1'); 85.6 (C-4'); 74.1 (C-2'); 70.8 (C-3'); and 61.8 (C-5). Based on these data, Compound 1 was identified as guanosine.

\section{Compound 2}

The HREIMS analysis of Compound 2 displayed a molecular ion peak at $\mathrm{m} / \mathrm{z}$ 266.2435 [M$\mathrm{H}]^{-}\left(\mathrm{C}_{10} \mathrm{H}_{13} \mathrm{~N}_{5} \mathrm{O}_{4}\right)$. One of the hydroxy signals disappeared in the ${ }^{1} \mathrm{H}-\mathrm{NMR}$ analysis of Compound 2 compared with Compound 1 . Methylene signals appeared at $\delta 40.0\left(\mathrm{C}-2^{\prime}\right)$ in the ${ }^{13} \mathrm{C}-\mathrm{NMR}$ analysis of Compound 2. Based on these data, Compound 2 was identified as 2'deoxyguanosine.

\section{Compound 3}

The HREIMS analysis of Compound 3 displayed a molecular ion peak at $\mathrm{m} / \mathrm{z}$ 266.2419 [M$\mathrm{H}]^{-}\left(\mathrm{C}_{10} \mathrm{H}_{13} \mathrm{~N}_{5} \mathrm{O}_{4}\right)$. The ${ }^{1} \mathrm{H}$ - and ${ }^{13} \mathrm{C}-\mathrm{NMR}$ spectra were in close agreement with those of a previous report [11]. The ${ }^{1} \mathrm{H}-\mathrm{NMR}\left(\delta, \mathrm{DMSO}-d_{6}, 300 \mathrm{MHz}\right)$ spectra revealed the following peaks: $8.34(1 \mathrm{H}$, $\mathrm{s}, \mathrm{H}-2) ; 8.12(1 \mathrm{H}, \mathrm{s}, \mathrm{H}-8) ; 7.36\left(2 \mathrm{H}, \mathrm{s},-\mathrm{NH}_{2}\right)$; $5.86\left(1 \mathrm{H}, \mathrm{d}, J=8.0 \mathrm{~Hz}, \mathrm{H}-1^{\prime}\right) ; 5.40\left(2 \mathrm{H}, \mathrm{m}, 2^{\prime}, 5^{\prime}-\right.$ $\mathrm{OH}) ; 5.16\left(1 \mathrm{H}, \mathrm{m}, 3^{\prime}-\mathrm{OH}\right) ; 4.59(1 \mathrm{H}, \mathrm{q}, J=5.6$ $\left.\mathrm{Hz}, \mathrm{H}-2^{\prime}\right) ; 4.12\left(1 \mathrm{H}, \mathrm{q}, J=3.0 \mathrm{~Hz}, \mathrm{H}-3^{\prime}\right) ; 3.94$ $\left(1 \mathrm{H}, \mathrm{q}, J=3.2 \mathrm{~Hz}, \mathrm{H}-4^{\prime}\right)$; $3.67\left(1 \mathrm{H}, \mathrm{m}, \mathrm{H}-5^{\prime} \mathrm{a}\right)$; and $3.55\left(1 \mathrm{H}, \mathrm{m}, \mathrm{H}-5^{\prime} \mathrm{b}\right)$. The ${ }^{13} \mathrm{C}-\mathrm{NMR}(\delta$, 
DMSO- $d_{6}, 300 \mathrm{MHz}$ ) spectra revealed the following peaks: 157.18 (C-6); 154.09 (C-2); 151.74 (C-4); 136.01 (C-8); 117.29 (C-5); 86.87 (C-1'); 85.66 (C-4'); 74.15 (C-2'); 70.82 (C-3'); and $61.87\left(\mathrm{C}-5^{\prime}\right)$. Based on these data, Compound 3 was identified as adenosine.

\section{Compound 4}

The HREIMS analysis of Compound 4 displayed a molecular ion peak at $\mathrm{m} / \mathrm{z} 241.2231$ [M$\mathrm{H}^{-}\left(\mathrm{C}_{10} \mathrm{H}_{14} \mathrm{~N}_{2} \mathrm{O}_{5}\right)$. The ${ }^{1} \mathrm{H}$ - and ${ }^{13} \mathrm{C}-\mathrm{NMR}$ spectra were in close agreement with those of a previous report [12]. The ${ }^{1} \mathrm{H}-\mathrm{NMR}\left(\delta, \mathrm{DMSO}-d_{6}, 300 \mathrm{MHz}\right)$ spectra revealed the following peaks: $11.25(1 \mathrm{H}$, $\mathrm{s}, \mathrm{NH}) ; 7.69(1 \mathrm{H}, \mathrm{s}, \mathrm{H}-6) ; 6.16\left(1 \mathrm{H}, \mathrm{m}, \mathrm{OH}-3^{\prime}\right)$; $5.21\left(1 \mathrm{H}, \mathrm{m}, 3^{\prime}-\mathrm{OH}\right) ; 5.00\left(1 \mathrm{H}, \mathrm{m}, 5^{\prime}-\mathrm{OH}\right) ; 4.23$ $\left(1 \mathrm{H}, \mathrm{d}, J=2.2 \mathrm{~Hz}, \mathrm{H}-3^{\prime}\right) ; 3.75\left(1 \mathrm{H}, \mathrm{m}, \mathrm{H}-4^{\prime}\right) ; 3.56$ $\left(1 \mathrm{H}, \mathrm{d}, J=11.6 \mathrm{~Hz}, 5^{\prime} \mathrm{b}\right) ; 1.92\left(2 \mathrm{H}, \mathrm{m}, \mathrm{H}-2^{\prime}\right)$; and $1.68\left(3 \mathrm{H}, \mathrm{d}, J=1.1 \mathrm{~Hz}, 5-\mathrm{CH}_{3}\right)$. The ${ }^{13} \mathrm{C}-\mathrm{NMR}(\delta$, DMSO- $d_{6}, 300 \mathrm{MHz}$ ) spectra revealed the following peaks: 163.8 (C-4); 150.5 (C-2); 136.2 (C-6); 109.5 (C-5); 87.3 (C-4'); 83.9 (C-1'); 70.5 $\left(\mathrm{C}-3^{\prime}\right)$; $61.4\left(\mathrm{C}-5^{\prime}\right)$; $39.4\left(\mathrm{C}-2^{\prime}\right)$; and $12.4\left(\mathrm{CH}_{3}\right)$. Based on these data, Compound 4 was identified as thymidine.

\section{Compound 5}

The HREIMS analysis of Compound 5 displayed a molecular ion peak at $\mathrm{m} / \mathrm{z} 243.2031$ [M$\mathrm{H}^{-}\left(\mathrm{C}_{9} \mathrm{H}_{12} \mathrm{~N}_{2} \mathrm{O}_{6}\right)$. The ${ }^{1} \mathrm{H}$ - and ${ }^{13} \mathrm{C}-\mathrm{NMR}$ spectra were in close agreement with those of a previous report [13]. The $\mathrm{H}-\mathrm{NMR}\left(\delta, \mathrm{DMSO}-d_{6}, 300 \mathrm{MHz}\right)$ spectra revealed the following peaks: $7.85(1 \mathrm{H}$, $\mathrm{d}, J=7.8 \mathrm{~Hz}, \mathrm{H}-6)$; $5.68(1 \mathrm{H}, \mathrm{d}, J=7.8 \mathrm{~Hz}, \mathrm{H}-5)$; $11.28(1 \mathrm{H}, \mathrm{s}, \mathrm{NH}) ; 5.76(1 \mathrm{H}, \mathrm{d}, J=5.2 \mathrm{~Hz}, \mathrm{H}-1)$; $3.99\left(1 \mathrm{H}, \mathrm{m}, \mathrm{H}-2^{\prime}\right) ; 3.95\left(1 \mathrm{H}, \mathrm{m}, \mathrm{H}-3^{\prime}\right) ; 3.82(1 \mathrm{H}$, $\mathrm{m}, \mathrm{H}-4)$; 3.53 (1H, m, H-5'a); 3.59 (1H, m, H-5'b); and $5.07-5.35\left(2 \mathrm{H}, \mathrm{m}, 2^{\prime}, 3^{\prime}, 5^{\prime}-\mathrm{OH}\right)$. The ${ }^{13} \mathrm{C}-$ NMR $\left(\delta\right.$, DMSO- $\left.d_{6}, 300 \mathrm{MHz}\right)$ spectra revealed the following peaks: 152.5 (C-2); 166.9 (C-4); 102.7 (C-5); 142.2 (C-6); 90.0 (C-1); 74.0 (C-2); 84.6 (C-3); 69.8 (C-4); and 61.2 (C-5). Based on these data, Compound 5 was identified as uridine.

\section{Compound 6}

The HREIMS analysis of Compound 6 displayed a molecular ion peak at $\mathrm{m} / \mathrm{z} 242.2131$ [M$\mathrm{H}^{-}\left(\mathrm{C}_{9} \mathrm{H}_{13} \mathrm{~N}_{3} \mathrm{O}_{5}\right)$. The ${ }^{1} \mathrm{H}$ - and ${ }^{13} \mathrm{C}-\mathrm{NMR}$ spectra were in close agreement with those of a previous report [14]. The ${ }^{1} \mathrm{H}-\mathrm{NMR}\left(\delta, 300 \mathrm{MHz}, \mathrm{DMSO}-d_{6}\right)$ spectra revealed the following peaks: $5.81(1 \mathrm{H}$, $\mathrm{d}, J=7.2 \mathrm{~Hz}, \mathrm{H}-5) ; 7.45(1 \mathrm{H}, \mathrm{d}, J=7.2 \mathrm{~Hz}, \mathrm{H}-6)$; $5.91\left(1 \mathrm{H}, \mathrm{d}, J=5.2 \mathrm{~Hz}, \mathrm{H}-1^{\prime}\right)$; and $3.52-5.00$ $\left(5 \mathrm{H}, \mathrm{m}, \mathrm{H}-2^{\prime}, 5^{\prime}\right)$. The ${ }^{13} \mathrm{C}$-NMR $(300 \mathrm{MHz}$, DMSO- $d_{6}$ ) spectra revealed the following peaks:
158.2 (C-2); 166.8 (C-4); 96.9 (C-5); 142.4 (C-6); 91.2 (C-1'); 74.8 (C-2'); 70.1 (C-3'); 84.6 (C-4'); and $61.6\left(\mathrm{C}-5^{\prime}\right)$. Based on these data, Compound 6 was identified as cytidine.

\section{Compound 7}

The HREIMS analysis of Compound 7 displayed a molecular ion peak at $\mathrm{m} / \mathrm{z} 203.2242$ [M$\mathrm{H}]^{-}\left(\mathrm{C}_{11} \mathrm{H}_{12} \mathrm{~N}_{2} \mathrm{O}_{2}\right)$. The ${ }^{1} \mathrm{H}$ - and ${ }^{13} \mathrm{C}-\mathrm{NMR}$ spectra were in close agreement with those of a previous report [15]. The ${ }^{1} \mathrm{H}-\mathrm{NMR}\left(\delta, \mathrm{DMSO}-d_{6}, 300 \mathrm{MHz}\right)$ spectra revealed the following peaks: $10.99(1 \mathrm{H}$, $\mathrm{s}, \mathrm{NH}) ; 7.15(1 \mathrm{H}, \mathrm{s}, \mathrm{H}-2) ; 7.05\left(2 \mathrm{H}, \mathrm{NH}_{2}\right) ; 6.81$ $(2 \mathrm{H}, \mathrm{d}, J=8.3 \mathrm{~Hz}, \mathrm{H}-4,7)$; and $6.66(2 \mathrm{H}, \mathrm{d}, J=$ $8.2 \mathrm{~Hz}, \mathrm{H}-5,6)$. The ${ }^{13} \mathrm{C}-\mathrm{NMR}\left(\delta\right.$, DMSO- $d_{6}, 300$ $\mathrm{MHz}$ ) spectra revealed the following peaks: 170.7 (COOH); 135.7 (C-9); 127.1 (C-8); 124.4 (C-2); 121.2 (C-4); 118.8 (C-5); 118.6 (C-6); 111.7 (C-7); 110.15 (C-3); 54.9 (C-11); and 26.5 (C-10). Based on these data, Compound 7 was identified as tryptophan.

\section{Compound 8}

The HREIMS analysis of Compound 8 displayed a molecular ion peak at $\mathrm{m} / \mathrm{z} 164.1862$ [M$\mathrm{H}]^{-}\left(\mathrm{C}_{9} \mathrm{H}_{11} \mathrm{NO}_{2}\right)$. The ${ }^{1} \mathrm{H}$ - and ${ }^{13} \mathrm{C}-\mathrm{NMR}$ spectra were in close agreement with those of a previous report [15]. The ${ }^{1} \mathrm{H}-\mathrm{NMR}\left(\delta, \mathrm{DMSO}-d_{6}, 300 \mathrm{MHz}\right)$ spectra revealed the following peaks: $7.36(5 \mathrm{H}$, $\left.\mathrm{m}, \mathrm{C}_{6} \mathrm{H}_{5}\right) ; 4.88(5 \mathrm{H}, \mathrm{m}, \mathrm{H}-8) ; 3.81(1 \mathrm{H}, \mathrm{s}, \mathrm{H}-8)$; $3.06\left(1 \mathrm{H}, \mathrm{m},-\mathrm{CH}_{2}\right)$; and $3.01\left(1 \mathrm{H}, \mathrm{m},-\mathrm{CH}_{2}\right)$. The ${ }^{13} \mathrm{C}-\mathrm{NMR} \quad\left(\delta, \mathrm{DMSO}-d_{6}, 300 \mathrm{MHz}\right)$ spectra revealed the following peaks: 173.9 (C-9); 135.2 (C-1); 129.4 (C-3, 5); 129.2 (C-2, 6); 127.7 (C-4); 56.1 (C-8); and 36.4 (C-7). Based on these data, Compound 8 was identified as phenylalanine.

\section{HPLC method validation}

\section{Optimization of the protocol}

Nucleosides are polar compounds; therefore, the initial concentration of Solvent A (acetonitrile) in the mobile phase was kept low to promote retention on the column. Nucleosides and amino acids are both weak acids; therefore, the retention time and peak shape on a reversedphase column can differ depending on the mobile phase [12]. Solvent B (15 mM ammonium acetate in water, $\mathrm{pH}=6.0$ ) was selected for its suitable chemical properties for these experiments. In the present study, two reversedphase columns (XTerra RP C18 and YMC Hydrosphere C18) were tested for the separation of nucleosides and amino acids isolated from bamboo shoot. The results indicated that the YMC Hydrosphere C18 column retained and 
separated the compounds better than the XTerra column. Figure 1 presents the HPLC chromatogram of six nucleosides and two amino acids and resolved on a YMC Hydrosphere C18 column at $254 \mathrm{~nm}$; phenylalanine was analyzed at $215 \mathrm{~nm}$.

\section{Linearity and sensitivity}

The linear relationships observed from the standard solutions of the compounds in the samples are presented in Table 1. The standard curves in the corresponding ranges had good linearity. The LOD and LOQ for the chromatographic experiments were determined separately at $\mathrm{S} / \mathrm{Ns}$ of 3 and 10 , respectively. LOD values ranged from 0.008 to $0.500 \mu \mathrm{g} / \mathrm{mL}$. $\mathrm{LOQ}$ values ranged from 0.025 to $1.600 \mu \mathrm{g} / \mathrm{mL}$. The linear range of phenylalanine was 3.12 to $200.00 \mu \mathrm{g} / \mathrm{mL}$, whereas the linear range of the other seven compounds was 0.22 to 60.00 $\mu \mathrm{g} / \mathrm{mL}$.

\section{Precision, reproducibility, and stability}

Table 2 presents the RSD values for intra-day and inter-day precision, reproducibility, and stability for the eight identified compounds they were all < 2.8, which suggests that the developed method is reproducible and stable.

\section{Recovery}

The compound recoveries were tested in bamboo shoot samples spiked with different amounts of mixed standard markers, and determined to be within $85.98-102.04 \%$. This indicated that the developed extraction method was reliable. Taken together with other control tests, all results indicated that the method performance was satisfactory.

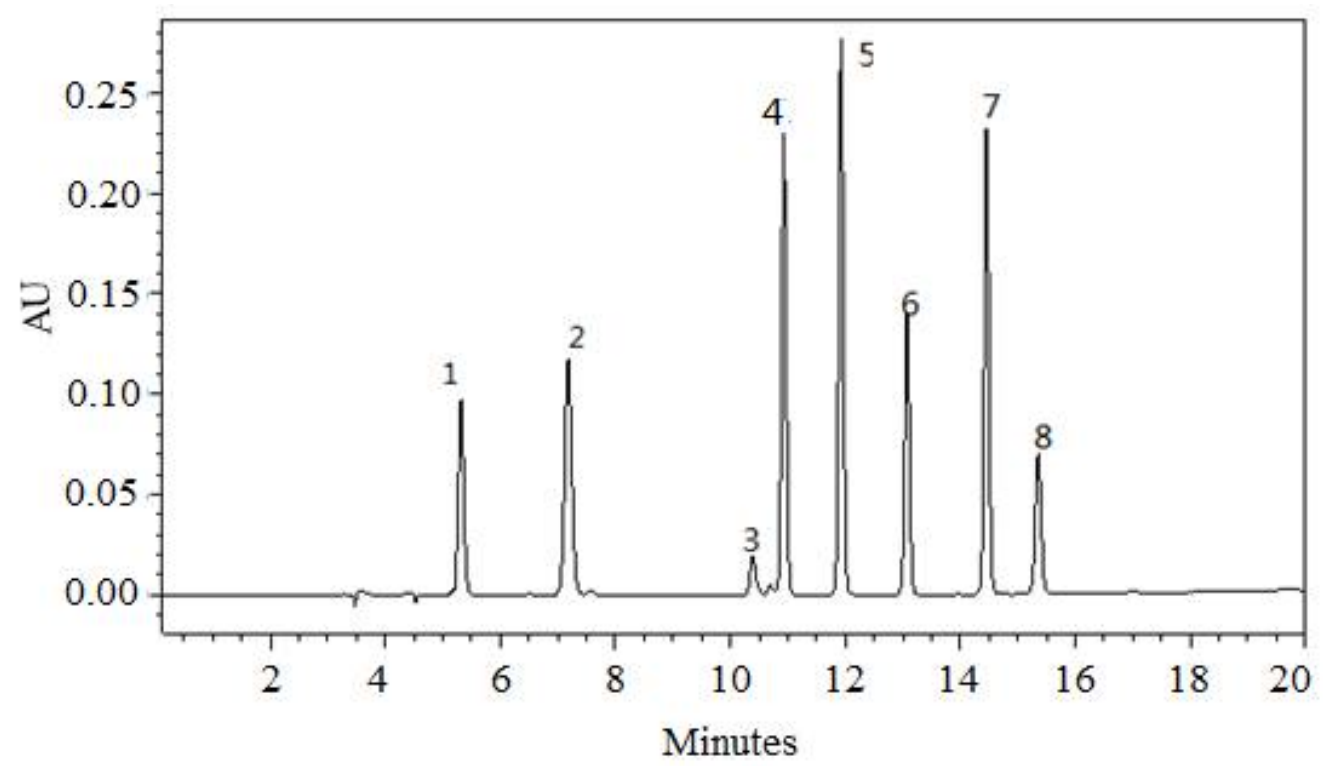

Figure 1: HPLC chromatogram and identification eight compounds: (1) cytidine, (2) uridine, (3) phenylalanine, (4) guanosine, (5) 2'-deoxyguanosine, (6) thymidine, (7) adenosine, and (8) tryptophan

Table1: Linear equations, LOD, LOQ, and linear ranges of eight compounds isolated from bamboo shoot

\begin{tabular}{lcccccc}
\hline Compound & $\begin{array}{c}\boldsymbol{\lambda} \\
(\mathbf{n m})\end{array}$ & $\begin{array}{c}\text { Regression } \\
\text { equation }\end{array}$ & $\boldsymbol{R}^{2}$ & $\begin{array}{c}\text { LOD } \\
(\boldsymbol{\mu} \mathbf{g} / \mathbf{m L})\end{array}$ & $\begin{array}{c}\text { LOQ } \\
(\boldsymbol{\mu} \mathbf{g} / \mathbf{m L})\end{array}$ & $\begin{array}{c}\text { Linear range } \\
(\boldsymbol{\mu} \mathbf{g} / \mathbf{m L})\end{array}$ \\
\hline Cytidine & 254 & $y=12,043 x+548$ & 0.9989 & 0.015 & 0.047 & $0.22-60.00$ \\
Adenosine & 254 & $y=25,613 x-622$ & 0.9992 & 0.010 & 0.031 & $0.22-60.00$ \\
Uridine & 254 & $y=19,484 x-497$ & 0.9999 & 0.008 & 0.025 & $0.22-60.00$ \\
Guanosine & 254 & $y=23,866 x-216$ & 0.9998 & 0.009 & 0.027 & $0.22-60.00$ \\
2'-deoxy- $_{\quad}^{\text {guanosine }}$ & 254 & $y=25,655 x+25$ & 0.9997 & 0.008 & 0.025 & $0.22-60.00$ \\
$\quad \begin{array}{l}\text { Thymidine } \\
\text { Tryptophan }\end{array}$ & 254 & $y=16,338 x-60$ & 0.9997 & 0.010 & 0.031 & $0.22-60.00$ \\
Phenylalanine & 254 & $y=9,083 x-971$ & 0.9996 & 0.024 & 0.075 & $0.22-60.00$ \\
\hline
\end{tabular}

$y$ is the peak area value; $x$ is the reference compound's concentration $(\mu \mathrm{g} / \mathrm{mL})$ 
Table 2: Experimental precision, reproducibility, and stability of eight compounds isolated from bamboo shoot

\begin{tabular}{lcccc}
\hline Compound & $\begin{array}{c}\text { Intraday } \\
\text { precision (RSD } \\
\%,\end{array}$ & $\begin{array}{c}\text { Interday } \\
\text { precision (RSD } \\
\%,\end{array}$ & $\begin{array}{c}\text { Reproducibility } \\
\text { (RSD \%, } \\
\boldsymbol{n = 5 )}\end{array}$ & $\begin{array}{c}\text { Stability } \\
\text { (RSD \%, } \\
\boldsymbol{n}=\mathbf{6})\end{array}$ \\
\hline Cytidine & 1.02 & $\boldsymbol{n = 5 )}$ & 1.22 & 1.74 \\
Adenosine & 0.67 & 2.23 & 0.87 & 2.31 \\
Uridine & 1.44 & 1.55 & 1.43 & 1.02 \\
Guanosine & 0.57 & 1.34 & 0.78 & 1.98 \\
2'-deoxyguanosine $^{\prime}$ Thymidine & 0.45 & 0.89 & 0.81 & 1.80 \\
Tryptophan & 1.11 & 2.45 & 1.21 & 2.68 \\
Phenylalanine & 1.74 & 2.04 & 0.68 & 2.78 \\
\hline
\end{tabular}

Table 3: Recovery of samples spiked with standard markers of eight compounds isolated from bamboo shoot

\begin{tabular}{cccc}
\hline Compound & Spiked quantity $(\boldsymbol{\mu g} / \mathbf{g})$ & Recovery $(\%)$ & RSD $(\%)$ \\
\hline \multirow{2}{*}{ Cytidine } & 60 & 102.35 & 3.33 \\
& 120 & 103.21 & 3.12 \\
Adenosine & 240 & 104.1 & 2.13 \\
& 60 & 91.34 & 1.77 \\
Uridine & 120 & 89.45 & 1.89 \\
& 240 & 92.94 & 3.13 \\
Guanosine & 60 & 95.5 & 2.33 \\
& 120 & 93.48 & 1.87 \\
2'-deoxyguanosine & 240 & 96.06 & 2.05 \\
& 60 & 99.26 & 0.98 \\
Thymidine & 120 & 96.68 & 0.67 \\
& 240 & 97.9 & 0.88 \\
& 60 & 95.24 & 4.11 \\
Tryptophan & 120 & 94.64 & 2.22 \\
& 240 & 93.48 & 1.97 \\
& 60 & 11.22 & 0.46 \\
Phenylalanine & 120 & 112.49 & 1.25 \\
& 240 & 109.39 & 0.53 \\
& 60 & 88.89 & 0.43 \\
& 120 & 90.74 & 0.56 \\
& 240 & 91.67 & 1.48 \\
& 100 & 89.43 & 1.88 \\
& 200 & 97.88 & 1.32 \\
& 400 & 85.72 & 0.81 \\
\hline
\end{tabular}

Table 4: Contents $(\mathrm{mg} / \mathrm{kg}) \pm \mathrm{RSD}$ of six nucleosides and two amino acids in shoots of four Phyllostachys bamboo species

\begin{tabular}{lcccc}
\hline Compound & $\begin{array}{c}\text { Phyllostachys } \\
\text { prominens }\end{array}$ & $\begin{array}{c}\text { Phyllostachys } \\
\text { iridescens }\end{array}$ & $\begin{array}{c}\text { Phyllostachys } \\
\text { pubescens }\end{array}$ & $\begin{array}{c}\text { Phyllostachys } \\
\text { praecox }\end{array}$ \\
\hline Cytidine & $32.56 \pm 0.54$ & $139.34 \pm 1.26$ & $294.69 \pm 1.17$ & $221.67 \pm 2.07$ \\
Adenosine & $22.41 \pm 0.43$ & $9.88 \pm 0.11$ & $\mathrm{ND}$ & $\mathrm{ND}$ \\
Uridine & $167.77 \pm 1.35$ & $511.57 \pm 3.40$ & $482.82 \pm 2.97$ & $105.62 \pm 1.67$ \\
Guanosine & $435.25 \pm 1.59$ & $49.54 \pm 0.78$ & $225.08 \pm 1.73$ & $472.11 \pm 3.51$ \\
2'-deoxyguanosine $_{\text {Thymidine }}^{43.38 \pm 0.43}$ & $\mathrm{ND}$ & $78.23 \pm 0.88$ & $95.16 \pm 1.05$ \\
Tryptophan & $59.88 \pm 0.42$ & $15.37 \pm 0.06$ & $112.45 \pm 1.38$ & $96.67 \pm 1.21$ \\
Phenylalanine & $547.48 \pm 3.15$ & $699.11 \pm 4.16$ & $530.32 \pm 3.80$ & $367.76 \pm 4.12$ \\
\hline
\end{tabular}

$N D$, not detected

\section{Application of the method}

The identification of investigated compounds was carried out by comparison of their retention time and their UV spectra with those obtained by injecting standards in the same conditions. The results of qualitative and quantitative analyses of six nucleosides and two amino acids isolated from bamboo shoots of four Phyllostachys species are presented in Table 4. Cytidine, 
uridine, guanosine, thymidine, tryptophan, and phenylalanine were all detected in Phyllostachys prominens, Phyllostachys iridescens, Phyllostachys pubescens, and Phyllostachys praecox. Adenosine was not detected in Phyllostachys pubescens and Phyllostachys praecox. Phenylalanine had the highest content in bamboo shoots of all four species.

\section{DISCUSSION}

Nucleosides are involved in the regulation of many physiological processes in the human body and exhibit multiple activities. There have been few studies of nucleosides in bamboo shoots. Chen et al isolated adenosine from Pleioblastus amarus bamboo shoots [16]. The current study developed a method for the extraction, isolation, and identification of six nucleosides and two amino acids from bamboo shoots. The method was validated and found to be reproducible. This study will facilitate further research on bioactive, nutritional, and medicinal compounds in bamboo shoots.

Bamboo shoot consumption is relatively modest in most countries outside Asia. The production of bamboo shoots is generally based on nonstandardized, traditional customs [2]. The development of this HPLC method for determination of cytidine, uridine, phenylalanine, guanosine, 2'-deoxyguanosine, thymidine, adenosine, and tryptophan from bamboo shoots could be applied for quality control of bamboo shoot production. This would add value to the final product. The guanosine contents of Phyllostachys prominens and Phyllostachys praecox were 435.25 and $472.11 \mathrm{mg} / \mathrm{kg}$ respectively. These values are higher than the guanosine contents in Ziziphus jujube (16.62 $185.72 \mathrm{mg} / \mathrm{kg}$ ) and Ganoderma (4.36 - 25.47 $\mathrm{mg} / \mathrm{kg}$ ) $[7,10]$. Food is one of the major resources of nucleosides and nucleotides for humans. Our study showed that bamboo shoots are rich sources of nucleosides. Therefore, bamboo shoots should be considered as excellent sources of nucleoside dietary supplements.

\section{CONCLUSION}

This study developed an HPLC method for the identification and quantitative analysis of six nucleosides and two amino acids from shoots of four Phyllostachys bamboo species. The method was tested and validated as reliable. Adenosine was previously identified in bamboo shoot, but this study identified guanosine, 2'deoxyguanosine, thymidine, uridine, cytidine, tryptophan, and phenylalanine for the first time.
The method is rapid, sensitive, and accurate, and can be applied for the determination of nucleosides in bamboo shoots.

\section{ACKNOWLEDGEMENT}

The authors would like to acknowledge the financial support from the National 948 Project of China (2012-4-16).

\section{REFERENCES}

1. Chongtham N, Bisht MS, Haorongbam S. Nutritional properties of bamboo shoots: potential and prospects for utilization as a health food. Compr. Rev. Food Sci. Food Safety 2011; 10: 153-169.

2. Choudhury D, Sahu JK, Sharma GD. Value addition to bamboo shoots: a review. J. Food Sci. Technol 2012; 49: 407-414.

3. Huang WS, Lu BY. Advances in Deep-Processing Technology of Bamboo Shoots Sci. Silv. Sin. 2008; 44(8): 118-123.

4. Yi TP, Shi JY, Ma LS, Wang HT, Yang L. Icono-graphia Bambusoidearum S inicarum. Science Press 2008; 342.

5. Anfossi G, Russo I, Massucco P, Mattiello L, Cavalot F, Balbo A. Adenosine increases human platelet levels of 3',5'-cGMP through nitric oxide: possible role in its antiaggregating effect. Thromb Res 2002; 105: 71-78.

6. Schmidt $A P$, Lara DR, FariaMaraschin J, Perla A S, Souza DO. Guanosine and GMP prevent seizures induced by quinolinic acid in mice. Brain Res 2002; 864: 40-43.

7. Guo S, Duan JA, Tang YP and Zhu ZH. Characterization of nucleosides and nucleobases in Fruits of Ziziphus jujube by UPLC-DAD-MS. J Agric Food Chem 2010; 58: 10774-10780.

8. Chen $P$, Li C, Liang SP, Song GQ, Sun $Y$, Shi $Y H$, Xu SL, Zhang JW, Sheng SQ. Characterization and quantification of eight water-soluble constituents in tubers of Pinellia ternate and in tea granules from the Chinese multiherb remedy Xiaochaihu-tang. $J$ Chromatogr B 2006; 843: 183-193.

9. Yuan JP, Zhao SY, Wang JH, Kuang HC, Liu X. Distribution of nucleosides and nucleobases in edible fungi. J Agric Food Chem 2008; 56: 809-815.

10. Chen $Y$, Bicker $W, W u$ JY, Xie MY, Lindner WG. Simultaneous Determination of 16 nucleosides and nucleobases by hydrophilic Interaction chromatography and its application to the quality evaluation of Ganoderma. J Agric Food Chem 2012; 60: 4243-4252.

11. Kinjo IJ, Matsumoto K, Inoue M. A new sapogenol and other constituents in Abri Semen, the seeds of Abrus precaturius L. Chem Pharm Bull 1991; 39: 116-119.

12. Shi XF, Tang XL, Li GQ. Study on chemical constitutes of Muriceides collaris from the south China.Chin $J$ Marine Drugs 2009; 28(2): 18-21.

Trop J Pharm Res, December 2015; 14(12): 2245 
13. Liu YF, Yang XW, Wu B. Chemical constituents of the flower buds of Tussilago farfara. J Chin Pharm Sci 2007; 16: 288-293.

14. Shi HM, Wen J, Tu PF. Chemical constitutes of Abrus cantoniensis. Chin Tradit Herbal Drug 2006; 37(11): 1610-1613.
15. Tian QB, Yang YP, He ZS, Ye Y. Chemical constituents of water-soluble part of Momordica charantia. Chin Tradit Herbal Drug 2005; 36(5): 657-658.

16. Chen J, Yao H, Lin HF, Hu CQ, Yong J. Chemical constituents of Pleioblastus amarus. Chin Tradit Herbal Drug 2005; 36(2): 184-185. 